\title{
Selection and Analysis for Hydraulic Rotary Apparatus of the Deck Hydraulic Crane
}

\author{
Wang Yongfu \\ College of Mechanical Engineering \\ Xijing University \\ Xi'an 710123, China \\ e-mail: wangyongfu2000@126.com \\ Lin Guomin \\ College of Mechanical Engineering \\ Xijing University \\ Xi'an 710123, China \\ e-mail:641922530@qq.com
}

\author{
Shang Miao \\ College of Mechanical Engineering \\ Xijing University \\ Xi'an 710123, China \\ e-mail: 445700839@qq.com \\ Zhou Fei \\ College of Mechanical Engineering \\ Xijing University \\ Xi'an 710123, China \\ e-mail: 743040357@qq.com
}

\begin{abstract}
The rotary is one of the important actions of deck hydraulic crane, and the hydraulic rotary apparatus is a driven source of rotary, so hydraulic rotary apparatus plays an important role on the rotary motion of the deck hydraulic crane for the stability and safety. When on the hydraulic rotary apparatus type selection, much more loads should be considered and the calculation for these loads is much more complicated. This paper makes a force analysis on the deck hydraulic crane when it is rotary then makes a selection on the key component of the rotary mechanism-hydraulic rotary apparatus for the deck hydraulic crane, and then has an explanation on the working principle of the hydraulic rotary apparatus which is selected. The selection plan has passed the examination of the China Classification Society, thus has an important reference value to the technicians and engineers who engage in deck hydraulic crane design.
\end{abstract}

Keywords-crane; ship; hydraulic; rotary; motor

\section{INTRODUCTION}

Deck hydraulic crane is a special crane which is installed on the ship. Associating with the ship, the crane will tilt laterally, tilt vertically and hoist between the waves. Since these movements will reduce the stability of the crane when it is in the operation, more factors must be considered when design crane, especially in the selection of hydraulic slewing apparatus. This paper takes YQ50 marine cantilever crane for example to make a detailed calculation and analysis of its hydraulic slewing apparatus, and make a description on the working principle of the hydraulic slewing apparatus [1].

\section{ANALYSIS OF THE CRANE}

\section{Usage}

The crane that this paper describes is used for hoisting in each ship. The safe working load is the maximum hoisting load under the environment of offshore and the wind power less than level four. structure

The crane consists of three parts as follows:

- The pedestal mechanism: the pedestal mechanism is a Cylinder which is made of steel plate. To install the crane, the pedestal mechanism must be welded with the deck of ship or connected with flange and bolts.

- The slewing mechanism: the slewing mechanism contains slewing cradle, hydraulic slewing apparatus, Slewing bearing and slewing gear which is installed on the hydraulic slewing apparatus. The slewing cradle which can also be used as hydraulic oil tank is a box type structure so is compact and small.

- The jib: the jib is also a box type structure. Its root segment is connected to the slewing cradle with a pin. And in the middle of the jib, it is connected to the end of the hydraulic cylinder with a pin, while the other end of the hydraulic cylinder is connected to the slewing cradle with a pin[2]. (As shown in Fig .1)

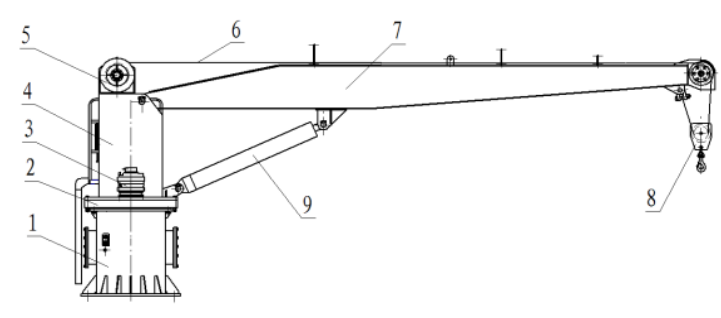

Figure 1. The structure of the crane

1.Pedestal 2.Slewing bearing 3.Hydraulic slewing apparatus 4.Slewing cradle 5.Hydraulic winch

\section{Movements}

There are three main movements of the deck cranehoisting, slewing and luffing as follows: 
- Hoisting winch is responsible for hoisting movement. Hydraulic hoisting apparatus is the driven force of the hoisting winch. The steel rope goes around the winch drum. When hydraulic hoisting apparatus is given power, makes the drum revolving. Through the steel rope, the deck hydraulic crane can do the hoisting movement.

- Hydraulic slewing apparatus is responsible for slewing movement. Slewing gear which is installed on the hydraulic slewing apparatus engaged with the gear of the slewing bring. Through the slewing gear and the slewing bring, the deck hydraulic crane can do the slewing movement.

- Through the hydraulic cylinder, the deck crane can do the luffing movement.

All the movements is controlled by the multiple directional control valve, work stress is controlled by the overflow valve.the driven power is from an electric motor and a hydraulic pump [3].

\section{Technical parameters}

- $\quad$ The safe working load is $50 \mathrm{KN}$;

- The hoisting height is $30 \mathrm{~m}$;

- The hoisting speed is $12 \mathrm{~m}$ per minute.

- The slewing speed is $1 \mathrm{rpm}$;

- The slewing angle is 360 degrees;

- Luffing time is 60 seconds;

- The minimum working radius is 3.2 meters;

- The maximum working radius is 10 meters;

- Tilt angle allows for ship is less than 5 degrees at heeling and less than 2 degrees at trim.

\section{LOAD ANALYSIS AND CALCULATION}

The spare parts gravity and center of gravity. (see Fig .2)

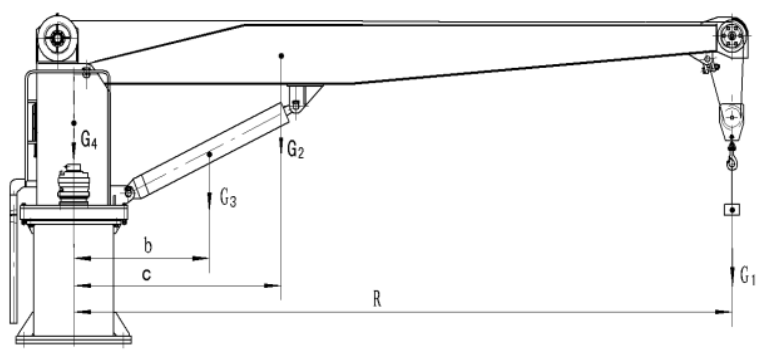

Figure 2. Gravity and the center

Crane is bearing the gravity of itself, the weight of each component and the torque caused by each component [4]. Through modeling and experiment data, the gravity and the center of gravity of each component is summarized as follows:

- The center of gravity of the hook, the pulley and rigging: $\mathrm{G}_{1}=2300 \mathrm{~N}, \mathrm{R}=10 \mathrm{~m}$.

- The center of gravity of the jib: $\mathrm{G}_{2}=30000 \mathrm{~N}, \mathrm{C}$ $=4.2 \mathrm{~m}$

- The total center of gravity of the hydraulic cylinder: $\mathrm{G}_{3}=12000 \mathrm{~N}, \mathrm{~b}=1.6 \mathrm{~m}$

- The total center of gravity of the slewing mechanism: $\mathrm{G}_{4}=33000 \mathrm{~N}$

\section{Crane load calculation}

Make a calculation for the horizontal reaction forces. There are horizontal reaction forces on the deck crane when it is operated because the ship is not balanced in the offshore ocean [6].

a) Calculation of the crane maximum angle:

The crane maximum angle is the angle between the center line of pedestal mechanism and sea level when deck crane is operated under the environment of offshore ocean and the wind power less than level four. Also the crane maximum angle equals the tilt angle allows for ship is 5 degrees at heeling and 2 degrees at trim. Now have a calculation for the crane maximum angle through geometric drawing. In the three-dimensional coordinates as shown in the Fig .3, the $\mathrm{X}$ axis direction shows the heeling tilt direction, and $\mathrm{Y}$ direction shows trim tilt direction. Line $\mathrm{OM}$ or line $\mathrm{OA}$ or line $\mathrm{OB}$ or line $\mathrm{OC}$ shows the condition of the base part center line when crane is at the condition of vertical or 5 degrees at heeling or 2 degrees at trim or the maximum angle. MOA is an angle of 5 degrees and MOB is an angle of 2 degrees, and $\mathrm{MOC}$ is the maximum angle which is unknown.

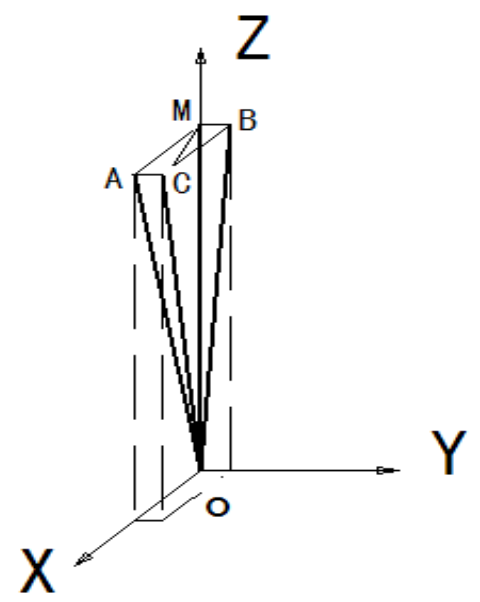

Figure 3. Crane tilt angle

Sets the length of $\mathrm{OM}$ to $\mathrm{L}$, so:

$$
\begin{gathered}
M A=\tan 5^{\circ} \bullet O M=\tan 5^{\circ} L \\
M B=\tan 2^{\circ} \bullet O M=\tan 2^{\circ} L
\end{gathered}
$$

According to the Pythagorean theorem:

$$
\begin{aligned}
& M C=\sqrt{M A^{2}+M B^{2}} \\
& O C=\sqrt{O M^{2}+M C^{2}}
\end{aligned}
$$

In the right angled triangle $\mathrm{OMC}$ :

$$
\tan \angle M O C=\frac{M C}{O M}
$$$$
\angle M O C=5.38^{\circ}
$$

So the crane maximum angle equals $5.38^{\circ}$.

b) Calculation of horizontal reaction force caused by hoisting load

Set the hoisting load to $\mathrm{F}_{1}$, so:

$$
\mathrm{F}_{1}=\mathrm{F}+\mathrm{G}_{1}=52300 \mathrm{~N}
$$

Eq.(6): F- safe working load, $F=50000 \mathrm{~N}$. 
Set the horizontal reaction force caused by hoisting load toF $\mathrm{F}_{21}$, so:

$$
\mathrm{F}_{21}=\mathrm{F}_{1} \times \sin \theta=4906 \mathrm{~N}
$$

Eq.(7): $\theta$ - the crane maximum angle, $\theta=5.38^{\circ}$.

c) Calculation of horizontal reaction force caused by components

Set the jib horizontal reaction force to $\mathrm{F}_{22}$, so:

$$
\mathrm{F}_{22}=\mathrm{G}_{2} \times \sin \theta=2814 \mathrm{~N}
$$

Set the hydraulic cylinder horizontal reaction force to $\mathrm{F}_{23}$, so:

$$
\mathrm{F}_{23}=\mathrm{G}_{3} \times \sin \theta=1126 \mathrm{~N}
$$

The inertial force caused by the slewing acceleration: The weight and the components generates additional inertial forces when crane is in the slewing action. load:

d) Calculation of inertial force caused by hoisting

Set the inertial force caused by hoisting load to $F_{31}$,

$$
\mathrm{F}_{31}=0.15 \times \mathrm{m} \times \mathrm{a}=769 \mathrm{~N}
$$

Eq.(10): g- acceleration of gravity, $g=10$; a-hoisting load acceleration, $a=0.098$.

e) Calculation of inertial force caused by jib

Set the inertial force caused by jib to $\mathrm{F}_{32}$, so:

$$
\mathrm{F}_{32}=0.15 \times \mathrm{m} \times \mathrm{a}=288 \mathrm{~N}
$$

f) Calculation of inertial force caused by hydraulic cylinder:

$$
\mathrm{F}_{33}=0.15 \times \mathrm{G}_{3} \times \mathrm{a}=81 \mathrm{~N}
$$

the load caused by wind:When the crane is operated, there are a lot of load caused by wind on the weight and components. Now make a calculation for these loads. weight

g) Calculation of wind load which is effecting on the

Set this load to $\mathrm{F}_{\mathrm{w} 1 \text {, so }}$

$$
F_{w 1}=\frac{300 \times F_{1}}{9.8 \times 1000}=1061 N
$$

h) Calculation of wind load which is effecting on the slewing component

The load directly in the boom:

$$
\mathrm{F}_{\mathrm{W} 2 \mathrm{~T}}=\mathrm{C} \times \mathrm{q} \times \mathrm{A}=535 \mathrm{~N}
$$

The load perpendicular to the boom:

$$
\mathrm{F}_{\mathrm{W} 2 \mathrm{C}}=\mathrm{C} \times \mathrm{q} \times \mathrm{A}_{1}=1338 \mathrm{~N}
$$

Eq.(14),(15): C- wind pressure coefficient, $C=1.82$; q- wind pressure, $\mathrm{q}=0.613 \mathrm{v}^{2}=245.2 \mathrm{MPa}$

$\mathrm{A}$ - the project area of slewing component directly in the boom, $\mathrm{A} \approx 1.2 \mathrm{~m}^{2}$;

$A_{1}$ - the project area of slewing component perpendicular to the boom, $\mathrm{A}_{1} \approx 3 \mathrm{~m}^{2}$.

\section{CALCULATION OF THE SLEWING TORQUE}

When crane is slewing, the weight and components is causing friction force torque on the slewing bearing, weight torque, components torque by ship tilt and inertial load torque by slewing acceleration. Now make a calculation for these torques.

\section{Calculation of the friction force torque}

Set the friction force torque to $\mathrm{M}_{1}$, so:
$\mathrm{M} 1=0.5 \times \mu \times \mathrm{D} \times \sum \mathrm{N}=15035 \mathrm{Nm}$

Eq.(17): $\mu$-the coefficient of friction of the slewing bearing, $\mu=0.01$;

D-the diameter of the slewing bearing rolling element, $\mathrm{D}=1.4 \mathrm{~mm}$.

$\sum \mathrm{N}$-stress of all rolling element,

$$
\begin{aligned}
\Sigma N & =\frac{F a}{\sin \gamma}\left(1-\frac{2 \times 1.4643}{\pi}\right) \\
& +\frac{2 \times K \times M \times \sin \psi}{1.4 \times \pi \times \sin \gamma} \\
& +\frac{4 \times F r}{\pi \times \cos \gamma} \\
& =2147911 N
\end{aligned}
$$

Eq.(18):

$F_{a}$-axial force of slewing bearing, $F_{a}=127300 N$;

$\mathrm{F}_{\mathrm{r}}$-radial force of slewing bearing, $\mathrm{F}_{\mathrm{r}}=16839 \mathrm{~N}$;

$\gamma$-angle pressure of rolling element;

$\mathrm{K}$-coefficient relates to the shape of rolling element; $\mathrm{M}$ - overturning moment of slewing bearing;

$$
\psi=\arccos \frac{D \times F_{a}}{K \times M}=85^{\circ}
$$

Calculation of torque caused by ship tilt

$$
\mathrm{M}_{2}=\mathrm{F}_{21} \cdot \mathrm{R}+\mathrm{F}_{22} \cdot \mathrm{c}+\mathrm{F}_{23} \cdot \mathrm{b}=62681 \mathrm{Nm}
$$

Calculation of torque caused by wind

$$
\mathrm{M}_{3}=\mathrm{F}_{\mathrm{w} 1} \cdot \mathrm{R}+\mathrm{F}_{\mathrm{w} 2 \mathrm{c}} \cdot \mathrm{c}=16229 \mathrm{Nm}
$$

Calculation of torque caused by slewing acceleration

$$
\mathrm{M}_{4}=\mathrm{F}_{31} \cdot \mathrm{R}+\mathrm{F}_{32} \cdot \mathrm{c}+\mathrm{F}_{33} \cdot \mathrm{b}=9029 \mathrm{Nm}
$$

Calculation of the total torque

$$
\mathrm{M}_{\text {total }}=\mathrm{M}_{1}+0.7 \mathrm{M}_{2}+0.7 \mathrm{M}_{3}+\mathrm{M}_{4}=79301 \mathrm{Nm}
$$

\section{SELECTED ROTARY APPARATUS}

The rotary gear ratio:

Eq.(24):

$$
\mathrm{i}=\mathrm{z}_{1} / \mathrm{z}_{2}=4.3
$$

$\mathrm{Z}_{1}$-number of teeth of slewing bearing; $\mathrm{Z}_{2}$-number of teeth of slewing gear.

Determine the output torque of the hydraulic rotary mechanism

The maximum turning torque:

$$
\mathrm{M}_{0}=\mathrm{M} / \mathrm{i}==19605 \mathrm{Nm}
$$

Choose the hydraulic slewing apparatus models

According to the hydraulic slewing apparatus technology parameter table, the hydraulic rotary apparatus models selected is HR5-10000. Its total displacement is $10234 \mathrm{ml} / \mathrm{r}$, continuous torque is $22000 \mathrm{Nm}$, range of speeds-0-40 r/min, continuous working pressure is $16 \mathrm{MPa}$; maximum working pressure is $25 \mathrm{MPa}$ 。 
Check the hydraulic slewing apparatus of the import and export maximum differential pressure

$$
\Delta P=\frac{2 \times \pi \times M}{q \times \eta}=14 M P a
$$

Hydraulic rotary equipment import and export of maximum differential pressure is $14 \mathrm{Mpa}$, it belongs to medium pressure range, and less than the continuous working pressure of hydraulic turning apparatus, so the choice of the hydraulic slewing apparatus meets the requirement [7-8].

\section{HR HYDRAULIC ROTARY APPARATUS AND APPLICATION IN THE CRANE}

\section{Properties and USES}

HR series hydraulic rotary apparatus is composed of BJM hydraulic motor with all kinds of valves piece and wet hydraulic brake and planetary gearbox. It has reliable mechanical braking, less radical dimension, less weight and higher torque. Its output shaft can bear larger radical and axial force. It has high starting efficiency and excellent low speed stability. It has high transmission efficiency, low noise level and good economy. Therefore it can be widely used in rotary system of deck crane [9-10].

\section{Shape (as shown in Fig .4)}

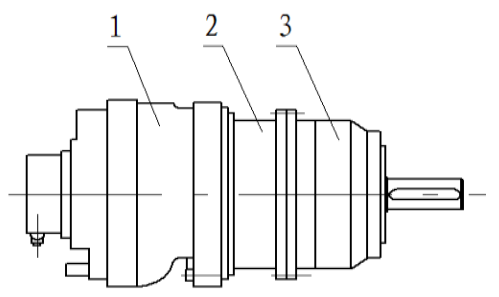

Figure 4. The shape

1.BJM series hydraulic motor 2 . Wet hydraulic brake 3.Planetary gearbox

Model specification (as shown in Fig .5)

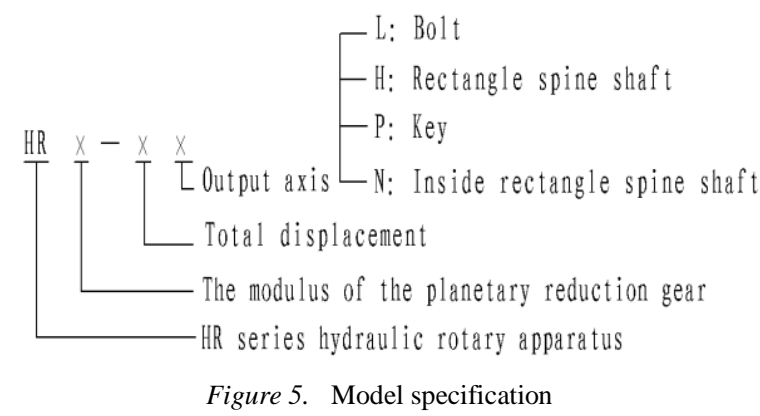

The installation of hydraulic slewing apparatus on the crane (as shown in Fig .6)

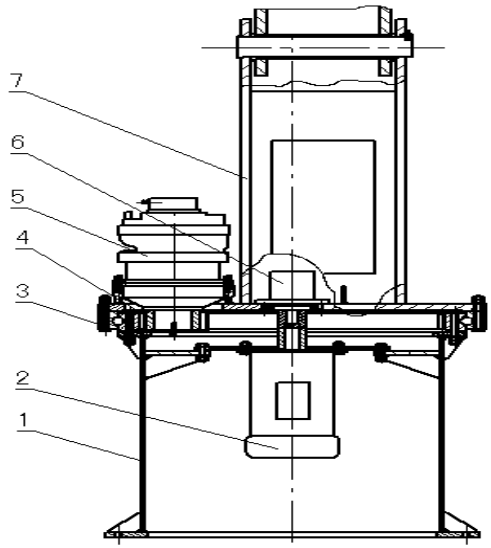

Figure 6. The installation on the crane

1.Pedestal 2.Electric motor 3.Slewing bearing 4.slewing gear 5.Hydraulic slewing apparatus 6.hydraulic pump 7.Slewing cradle

\section{CONCLUSION}

Analyze the force of a deck hydraulic reasonably, on the basis of which to select hydraulic slewing apparatus models. The selection plan has passed the examination of the China Classification Society. After installation and putting into use, its selection is proved to be reasonable, reliable, and compact, and accord with deck hydraulic crane operating conditions. Calculation and selection of the step as to meet the requirements of technical specification. So this paper has an important reference value to the technicians and engineers who engage in deck hydraulic crane design.

\section{REFERENCES}

[1] China Classification Society. Rules for lifting appliances of ships and offshore installations [M]. Beijing: China Communication Press, 2007..

[2] Zhang Zhiwen, Yu Heqian, Wang Jinnuo. Crane design manual [M]. Beijing: China Railway Publishing House, 2013.

[3] Register of shipping of the People's Republic of China, Legal inspection rules for ships and offshore facilities [M]. Beijing: China Communication Press, 2005.

[4] GB/T3811-2008, Crane design specification [S]. Beijing: China standard publishing house, 2008.

[5] GB/T12932-2010, Shipbuilding jib cranes [S].Beijing: China standard publishing house, 2010.

[6] Lu Zhizhen, Li Xuehu, Shu Xiyong, Wang Chenglong. Marine telescopic folding crane hydraulic system design [J]. Modem Manufacturing Engineering, 2012, (3):110-113.

[7] Wei Jianhua, Xiao Hui. Hydraulic system design of H3026000-000 deck crane $[\mathrm{J}]$. Hydraulic and pneumatic transmission, 2010, (6) 15-17.

[8] Wang hongbo. Improment of the ship crane hydraulic system [J].Hydraulic and pneumatic transmission, 2012, (2): 64-65.

[9] Li Zhuangyuan, Ge Yiyuan. Hydraulic components and systems [M]. Beijing: Mechanical industry press, 2010.

[10] Cheng Daxian. Mechanical design manual, the $5^{\text {th }}$ edition, vol.2 [M]. Beijing: Chemical industry press, 2010. 